\title{
Suicide: Dying for an Education
}

\author{
Jason L. Daugherty ${ }^{1} \&$ LaVelle Hendricks ${ }^{1}$ \\ ${ }^{1}$ Department of Psychology, Counseling, and Special Education, College of Education and Human Services, Texas \\ A\&M University-Commerce, Commerce, TX, USA \\ Correspondence: LaVelle Hendricks, EdD, Associate Professor of Counseling, Department of Psychology, \\ Counseling, and Special Education, College of Education and Human Services, Texas A\&M University-Commerce, \\ Commerce, TX, USA.
}

Received: October 23, 2015

Accepted: November 12, 2015

Online Published: July 20, 2016

doi:10.5430/irhe.v1n2p161

URL: http://dx.doi.org/10.5430/irhe.v1n2p161

\begin{abstract}
In recent studies and surveys, suicide among college students has shown to be at alarming rates. Suicide ranks as the second leading cause of death among college students. Yet for young adults in this same age group, not attending school, it is only the third. (Hirsch, Conner, \& Duberstien, 2007) Although suicide rates have been on the decline since 1976 (Schwartz, 2006), it is still an issue that must be dealt with on a daily basis. With over 14 million students currently in school (Hass, Silverman, \& Koestner, 2012), it is imperative that we continue to focus on this problem in order to prevent unnecessary deaths.
\end{abstract}

Keywords: suicide, college students, depression

\section{Introduction}

14 million students are currently enrolled in colleges across the United States (Hass, Pollinger, \& Koestner, 2013). College can be a stressful environment to adjust to. Concerns about one's grades, financial problems, and social pressures are just a few of the issues that young people have to contend with. Other factors that can lead to suicide are depression and other severe mental disorders. Pair these with the lack of a support structure that some students no longer have access to, and one can see how this could present a problem. There are resources available at most universities, but these are not always utilized. An effort needs to be made to get the word out that help is available. There are many different factors that can be associated with suicide, as well as multiple warning signs that can help identify at-risk individuals. Another aspect that needs to be considered is the fact that suicidal thoughts are often the result of some other underlying issue. In some cases this can, not only put the individual at risk, but endanger those around them as well. University counseling centers need to be aware of current trends in emotional disturbances, and be on the lookout for the many red flags associated with suicide and other extreme actions.

\section{Prevalence and Demographics}

Suicide rates among individuals age 15-24 years of age have shown to be as high as 7.5 per 100,000. Persons of the same age group not attending school are around 15 per 100,000 (Arria, O'Grady, Caldeira, Vincent, Wilcox, \& Wish, 2009). Yet even though this rate of students is lower, suicide is still considered to be the second leading cause of death in individuals attending school. Ethnic, cultural, and gender differences also are represented in suicide rates. America itself consists of a vast plethora of varying cultures and ethnic groups. There is also the large number of international students who choose to attend school in the United States. Due to this, it is important to understand that having knowledge of these different backgrounds is essential in understanding suicide within the academic setting. One such example of this is Japanese students. The view of suicide, by some traditional Japanese, can differ from that of Americans. Some areas within the Japanese culture, view suicide as a means of shame prevention and domination over one's will. Without the negative ideology associated with suicide that most Americans have, this can cause an individual to be more prone to commit suicide. This can be seen in the fact that in Japan, suicide is the leading cause of death. Rates of suicide in that area sit at 13.7 per 100,000, in comparison to 7.5 in the U.S. (Saito, Klibert, \& Langhinrichsen-Rohling, 2013). The social acceptance of suicide may have something to do with these higher rates. Another area in which we see statistical differences based on ethnicity, is among Black American college students. Approximately $8 \%$ of individuals who were polled within this demographic reported making a suicide attempt (Wang, Lightsey, Tran, \& Bonaparte, 2013). This is far lower than that of white college students of 
the same age group. In 2005, the number of suicides committed by blacks was only 1,992 . In contrast, those of whites were a staggering 29,527. With so many different cohorts, it is important to have an understanding about what role this might play in the screening and treatment of individuals who may be suicidal.

Aside from the broader area of cultural and ethnic differences, there are other factors to consider. Depression, alcohol and drug use, and social support problems can lead to suicidal thoughts and behaviors (Lamas \& Malone, 2011). An issue with identifying areas of concern within these factors is that many times college students fail to admit to having a problem. Announcing that one has an alcohol or drug problem, or is depressed, is often perceived to be viewed negatively by others. With heavy alcohol and drug use being a leading contributor to depressive symptoms, and the fact that depression alone can lead to suicide, one can see how the two can intertwine to create a volatile situation. Social support, or the lack thereof, can have a huge impact on suicidal thoughts in students. When a young adult moves away from home to begin school, they sometimes do not have access to the same level of structure and emotional support they had grown accustomed to throughout their lives. This can create difficulties in dealing with the everyday struggles involved with life. Without the proper tools to combat these feelings, many young people quickly spiral out of control. Factors such as loneliness, academic performance, financial worries, relationships, and hopelessness have all been cited as causes of depression by college students (Furr, Wesefeld, McConnell, \& Jenkins, 2001). Having to cope with these stressors, without parents or other loved ones available, can lead to a sense of feeling lost with nowhere to turn. This becomes especially relevant when looking at international students who sometimes have little to no contact with family who are potentially thousands of miles away.

\section{Suicide and Violence against Others}

One major issue that has recently come to light due to modern media coverage, is violence against others during the suicide act. This scenario occurs when, for whatever reason, and an individual chooses not only to take their own life, but others' as well. One such incident occurred in Newtown Connecticut on December 14, 2012. At approximately 9:30 a.m., after killing his mother, Adam Lanza walked into Sandy Hook elementary school and began shooting. The tragedy ended with Lanza killing 26 individuals at the school, 20 of which were children, before taking his own life. (Berger \& Santora, 2013) This horrible act of violence not only left many people without loved ones, but opened the door to numerous unanswered questions: What can drive an individual to commit acts of terror such as this? Were there any warning signs that could have been spotted beforehand, and how can we prevent something like this from happening again? In actuality these signs had been present. Lanza spent most of his time alone, communicating with family members via email only. Investigations showed that a pattern of violent and suicidal ideology had been present throughout his life. Despite the presence of these, be it due to a lack of understanding or knowledge, nobody chose to seek help for Lanza. Had these warning signs been identified earlier, so many lives could have possibly been saved.

\section{Treatment and Prevention}

The number of cases, such as the one previously mentioned, is high. Yet our ability to identify, intervene, and treat those suffering from depression and suicidal ideology grows exponentially with each incident. If we make an effort to study and learn from them, our universities can improve upon old and/or implement new programs to combat the problem. Many such programs already exist. Some universal programs currently in use are the Signs of Suicide Prevention or (SOS) and the Suicide Prevention Program. The goal of these programs is to reduce suicidal behaviors by changing individual attitudes about suicide (Robinson, Cox, Malone, Williamson, Baldwin, Fletcher, \& O’Brien, 2013). Other programs such as Project SOAR and Peer Gatekeeper Train seek to increase public knowledge about suicide risk factors and warning signs (Robinson, Cox et al., 2013). With proper utilization, these various programs can help bring awareness to college students as well as counselors and faculty members. As awareness increases, so too does the ability to prevent future suicides.

\section{Conclusion}

With suicide being the second leading cause of death among college students, it is important to take a closer look at the phenomenon. Each individual who acts upon a suicidal thought will have their own personal reasons for doing so. Yet there are universal reasons that that each case can be attributed to such as loss, loneness, or the feeling of failure. As we begin to better understand the universal risk and warning signs, we will be more capable of implementing them into a prevention strategy. Prevention cannot be our only focus. We must also improve upon our ability to educate the public in identifying at-risk individuals. Better public awareness means more eyes to observe and possibly spot problems before they get out of hand. As recent events have shown, suicide is not only a problem for those that choose to take their own lives, but can present disastrous consequences for others as well. All parties involved suffer when a suicide occurs. Whether it is the families of a loved one choosing to end their life, or victims 
of violent suicidal acts, far more are affected than he who makes the decision to die. In an effort to end their troubles, those who commit suicide generally leave the world a far more troubled place.

\section{References}

Arria, Amelia, M., O’Grady, Kevin, E., Caldeira, Kimberly, M., Vincent, Kathryn, B., Wilcox, Holly, C., \& Wish, Eric, D. (2009). Suicide Ideation Among College Students: A Multivariate Analysis. Archives of Suicide Research, 13, 230-246. http://dx.doi.org/10.1080/13811110903044351

Burger, J., \& Santora, M. (2013, November 25). Chilling Look at Newtown Killer, but No "Why". NyTimes. Retrieved from www.nytimes.com

Furr, Susan, R., McConnell, Gaye, N., Westefeld, John, S., \& Jenkins, Marxhall, J. (2001). Suicide and Depression Among College Students: A Decade Later. Proffessional Psychology: Research and Practice, 32(1), 97-100. http://dx.doi.org/10.1037/0735-7028.32.1.97

Haas, Pollinger, Ann., Silverman, Morton, M., \& Koestner, Bethany. (2013). College Students. Saving Lives, 2, 1-8. Retrieved from www.omh.ny.gov/omhweb/savinglives/volume2/college_students.html

Hirsch, Jameson, K., Conner, Kenneth, R., \& Duberstein, Paul, R. (2007). Optimism and Suicide Ideation Among Young Adult College Students. Archives of Suicide research, 11, 177-185. http://dx.doi.org/10.1080/13811110701249988

Lamis, Dorian, A., \& Malone, Patrick, S. (2011). Alcohol-Related Problems and Risk of Suicide among College Students: The Mediating Roles of Belongingness and Burdensomeness. Suicide and Life-Threatening Behavior, 41(5), 543-553. The ASmerican Association of Suicidology, 2011.

Madge, Nicola. (1999). Youth suicide in an international context. European Child \& Adolescent Psychiatry, 8, 283-291.

Mei-Chuan Wang, Owen Richard Lightsey Jr., Kimberly K. Tran, \& Taria S. Bonaparte. (2013). Examining Suicide Protective Factors Among Black College Students. Death Studies, 37(03), 228-247. http://dx.doi.org/10.1080/07481187.2011.623215

Robinson, Jo, Cox, Georgina, Malone, Aisling, Williamson, Michelle, Baldwin, Gabriel, Fletcher, Karen, \& O'Brian, Matt. (2013). A Systematic Review of School-Based Interventions Aimed at Preventing, Treating, and Responding to Suicide-Related Behavior in Young People. Crisis, 34(3), 164-182. http://dx.doi.org/10.1027/0227-5910/a000168

Saito, Motoko, Klibert, Jeffery, \& Langhinrichsen-Rohling. (2013). Suicide Proneness in American and Japanese College Students: Associations with Suicide Acceptability and Emotional Expressivity. Death Studies, 37(9), 848-865. http://dx.doi.org/10.1080/07481187.2012.699910

Swogger, M.T., Van Orden, K.A., \& Conner, K.R. (2013, August 26). The Relationship of Outwardly Directed Aggresion to Suicidal Ideation and Suicide Attempts across Two High-Risk Samples. Psychology of Violence. Advance online publication. http://dx.doi.org/10.1037/a0033212 